\title{
QUALITY OF LIFE IN INDIVIDUALS WITH AND WITHOUT DIABETES MELLITUS- A CASE CONTROL STUDY
}

Anitha Rayirala1, Krishna Sahithi Jujjavarapu², Kottepogu Sreedhar ${ }^{3}$, Cuddapah Gaurav Venkat ${ }^{4}$, Yarrarapu Satya Naga Srinivas ${ }^{5}$

${ }_{1}^{1}$ Associate Professor, Department of Psychiatry, Rajiv Gandhi Institute of Medical Sciences, Adilabad, Telangana, India.

${ }^{2}$ Assistant Professor, Department of Psychiatry, Kamineni Academy of Medical Sciences and Research Centre, Hyderabad, Telangana, India.

${ }^{3}$ Consultant Physician and Diabetologist, Department of General Medicine, Vijaya Hospital, Madinaguda, Hyderabad, Telangana, India. ${ }^{4}$ House Surgeon, Kamineni Academy of Medical Sciences and Research Centre, Hyderabad, Telangana, India.

${ }_{5}^{5}$ House Surgeon, Andhra Medical College, Vishakhapatnam, Andhra Pradesh, India.

\section{BACKGROUND}

ABSTRACT

Diabetes Mellitus (DM) is one of the common chronic medical conditions affecting approximately 347 million people worldwide. The mere presence of diabetes deteriorates a person's Quality of Life (QoL). Diabetic's QoL becomes worse when complications start to develop, or comorbidities co-exist. Numerous studies have recognised diabetes to be adversely affecting the quality of life. Aims- The present study was undertaken to compare the quality of life in type 2 diabetes patients and non-diabetic patients.

\section{MATERIALS AND METHODS}

100 cases of type II diabetes mellitus and 100 non-diabetic age-matched controls including both males and females were assessed for quality of life. Quality of sleep was assessed by 36-item Short Form Survey Instrument (SF-36), a self-reporting instrument.

\section{RESULTS}

Demographic data was not significantly different between cases and controls. Quality of sleep was significantly lower in cases when compared to controls.

\section{CONCLUSION}

The quality of life in diabetics is significantly lower in comparison to non-diabetic patients.

\section{KEY WORDS}

Diabetes Mellitus, Diabetics, Non-Diabetics, SF-36.

HOW TO CITE THIS ARTICLE: Rayirala A, Jujjavarapu KS, Sreedhar K, et al. Quality of life in individuals with and without diabetes mellitus- a case control study. J. Evolution Med. Dent. Sci. 2018;7(43):4664-4667, DOI: 10.14260/jemds/2018/1040

\section{BACKGROUND}

Currently, India is considered the 'Diabetes Capital' of the world. This is because the largest number of people with diabetes live in this country. The International Diabetes Federation estimated that the number of diabetics in India has doubled between 1995 and 2005, and by 2025 it would reach a figure of about 70 million.1,2,3,4 India plays a unique role in the diabetes picture of the world. Compared to any other ethnic groups, Asian Indians have a higher propensity to insulin resistance, diabetes mellitus and coronary artery disease. ${ }^{5}$

Quality of Life (QoL) of the patients with diabetes mellitus represents personal perceptions of life experience, social, vocational and domestic functioning against hope and ideals from aspects of physical, psychological, relationships, environmental and spiritual domains. 6,7

'Financial or Other Competing Interest': None.

Submission 13-09-2018, Peer Review 08-10-2018,

Acceptance 13-10-2018, Published 22-10-2018.

Corresponding Author:

Dr. Krishna Sahithi Jujjavarapu,

C-408, Suha Apartments,

Hanuman Nagar,

Manikonda-500089,

Telangana,

India.

E-mail: krishnasahiti15@gmail.com

DOI: $10.14260 /$ jemds/2018/1040

(c) (i) (3) $\Theta$
A large body of literature has focused on the impacts of diabetes mellitus of both type 1 and type 2 on patients, albeit in vast aspects and contexts of life,8,9 and the associations with QoL, self-efficacy and disease control for adult patients with T2D. Moreover, patients who perceived higher levels of QoL also showed that they had better social support, acceptance of the seriousness and consequences of the disease and had less difficulty in managing their diabetes. ${ }^{10}$

\section{Aims and Objectives}

- $\quad$ To study the Quality of Life in adults with type 2 diabetes.

- $\quad$ To compare the Quality of Life between diabetic and non-diabetic adults.

\section{MATERIALS AND METHODS}

\section{Study Design}

A case-control study.

\section{Study Site}

The study was conducted at Vijaya Hospital, Madinaguda, Hyderabad, India.

\section{Study Sample}

100 diabetic patients as cases and 100 non-diabetic patients as controls.

\section{Study Tools}

- 36-item Short Form Survey Instrument (SF-36), a selfreporting instrument for measuring quality of life. 
The SF-36 contains 36 items evaluating 8 dimensions of health: Physical functioning, role limitations due to physical problems, bodily pain, general health perceptions, vitality, social functioning, role limitations due to emotional problems and mental health. Each dimension is scored on a 0 to 100 scale with higher scores indicating better functioning. In addition, the SF-36 includes 2 composite summary scores: The Physical Component Score (PCS) and the Mental Component Score (MCS). The PCS and MCS are standardised to a mean (SD) of 50,11 with lower scores indicating more significant dysfunction.

\section{Sampling Technique}

The sample size was selected for convenience.

\section{Inclusion Criteria/ Cases}

- $\quad$ Type 2 diabetes diagnosed by physician.

- $\quad$ Age $>25$, both male and female.

- Duration of diabetes, minimum 1 year.

- On oral or injectable medication.

- Given informed consent.

\section{Controls}

- $\quad$ Age $>25$, both male and female.

- $\quad$ HbA1c levels $<5.6$

\section{Exclusion Criteria}

History of diabetes less than 1 year.

\section{Statistical Analysis}

- Statistics were done by using means and standard deviations.

- Tests of comparison for continuous variables: Independent student T-test.

- $\quad$ Software tools used were MS-Excel and R programming language.

\section{RESULTS}

The mean age of diabetics is (47.7 \pm 14.37$)$ yrs. and in Dr. Faith et al study, the mean age is 63.9 years which is not comparable. ${ }^{12}$ In our study for non-diabetics, mean age is (37.72 \pm 12.87 ) yrs. Out of 100 diabetic cases $24 \%$ of diabetic patients are in 24 to 34 years' age group, $20 \%$ in 35 to 44 , $22 \%$ are in 45 to $54,18 \%$ in 55 to 64 and $16 \%$ in 65 and above. Out of 100 control group, $4 \%$ of non-diabetic patients are in 24 to 34 years' age group, $26 \%$ in 35 to $44,44 \%$ are in 45 to $54,6 \%$ in 55 to 64 and $20 \%$ in 65 and above. In diabetic patients $60 \%$ are females and $40 \%$ are males, whereas in control group $66 \%$ are females and $34 \%$ are males.

\begin{tabular}{|c|c|c|c|c|}
\hline Scale & Items & Alpha & Mean & SD \\
\hline Physical functioning & 10 & 0.8797 & 56.45 & 2.53099 \\
\hline Role functioning/ physical & 4 & 0.85406 & 68.5 & 4.38006 \\
\hline Role functioning/ emotional & 3 & 0.7754 & 62.3333 & 4.42502 \\
\hline Energy/fatigue & 4 & 0.65889 & 60.5 & 1.72531 \\
\hline Emotional well-being & 5 & 0.48534 & 69.36 & 1.78806 \\
\hline Social functioning & 2 & 0.99839 & 62 & 0.70318 \\
\hline Pain & 2 & 0.71717 & 61.5 & 1.12001 \\
\hline General health & 5 & 0.49475 & 51.7 & 1.39453 \\
\hline Health change & 1 & & 46.5 & 1.00629 \\
\hline
\end{tabular}

\begin{tabular}{|c|c|c|c|c|}
\hline Scale & Items & Alpha & Mean & SD \\
\hline Physical functioning & 10 & 0.92389 & 64.15 & 3.2275 \\
\hline Role functioning/ physical & 4 & 0.81793 & 75 & 4.23434 \\
\hline Role functioning/ emotional & 3 & 0.82353 & 70.6667 & 4.39534 \\
\hline Energy/ fatigue & 4 & 0.7822 & 69.4 & 2.52223 \\
\hline Emotional well-being & 5 & 0.64583 & 67.76 & 2.02905 \\
\hline Social functioning & 2 & 0.99558 & 63.75 & 1.19051 \\
\hline Pain & 2 & 0.64683 & 64.95 & 1.67422 \\
\hline General health & 5 & 0.68456 & 52.1 & 1.76951 \\
\hline Health change & 1 & & 52.5 & 1.52835 \\
\hline \multicolumn{5}{|c}{ Non-Diabetics } \\
\hline \multicolumn{5}{|c}{} \\
\hline
\end{tabular}

Life Quality of Non-Diabetics is better than that of Diabetics (with Reference to Mean and SD)

- The physical functioning of Diabetics (56.45 \pm 2.53$)$ is less than Non-Diabetics (64.15 \pm 3.23$)$.

- The role functioning or physical (4 items) of Diabetics $(68.5 \pm 4.38006)$ is less than Non-Diabetics $(75 \pm$ 4.23434).

- The role functioning or emotions of Diabetics (62.33 \pm $4.42)$ is less than Non-Diabetics (70.66 \pm 4.39$)$.

- The energy of Diabetics $(60.50 \pm 1.72)$ is less than NonDiabetics (69.4 \pm 2.52$)$.

- $\quad$ The emotional well-being of Diabetics (69.36 \pm 1.78$)$ is more than Non-Diabetics ( $67.76 \pm 2.02)$.

- The social functioning of Diabetics $(62 \pm 0.70)$ is less than Non-Diabetics $(63.75 \pm 1.19)$.

- The pain domain of Diabetics $(61.50 \pm 1.12)$ is less than Non-Diabetics $(64.95 \pm 1.67)$.

- The general health of Diabetics (51.70 \pm 1.39$)$ is less than Non-Diabetics $(52.10 \pm 1.76)$.

- The health change of Diabetics (46.5 \pm 1.00$)$ is less than Non-Diabetics $(52.5 \pm 1.52)$.

\section{Age/ PCS}

In our study, $16 \%$ of diabetic cases are aged 65 and above. Among them, $65 \%$ of them are having poor quality of life. In non-diabetic controls $20 \%$ of cases are aged 65 and above and among them $60 \%$ of them are having poor quality of life.

\section{MCS}

In our study, $16 \%$ of diabetic cases are aged 65 and above. Among them, $63 \%$ of them are having poor quality of life. In non-diabetic controls $20 \%$ of cases are aged 65 and above and among them $10 \%$ of them are having poor quality of life.

The percentage of diabetic and non-diabetic patients in physical component score aged 65 and above, scoring poor quality of life is nearly similar, whereas in mental component score there is wide range of difference between cases and controls.

\section{Sex/ PCS}

In our study, $18 \%$ of diabetic cases have poor quality of life and among them $64 \%$ are females which is comparable to $55.4 \%$ in Aikaterini Trikkalinou's study. ${ }^{13}$ In non-diabetic controls, $22 \%$ of cases have poor quality of life and among them $56 \%$ are females.

\section{MCS}

In our study, $16 \%$ of diabetic cases have poor quality of life and among them $50 \%$ are females. In non-diabetic controls, $12 \%$ of cases have poor quality of life and among them $67 \%$ are females. 
From this we can infer that females have poorer quality of life in cases as well as controls when compared to males in physical and mental component scoring.

\section{Occupation/ PCS}

In our study, $18 \%$ of diabetic cases have poor quality of life and among them $67 \%$ are unemployed and $22 \%$ are employed. In non-diabetic controls, $22 \%$ of cases have poor quality of life and among them $45 \%$ are employed and $55 \%$ are unemployed.

\section{MCS}

In our study, $16 \%$ of diabetic cases have poor quality of life and among them $47 \%$ are unemployed and $25 \%$ are employed. In non-diabetic controls, $12 \%$ of cases have poor quality of life and among them $67 \%$ are employed and $33 \%$ are unemployed.

From this we can infer that unemployment is a risk factor, which can affect the quality of life.

\section{Type of Family/ PCS}

In our study, $18 \%$ of diabetic cases have poor quality of life and among them $78 \%$ belong to joint family and $22 \%$ belong to nuclear family. In non-diabetic controls, $22 \%$ of cases have poor quality of life and among them $64 \%$ belong to joint family and $46 \%$ belong to nuclear family.

\section{MCS}

In our study, $16 \%$ of diabetic cases have poor quality of life and among them $50 \%$ belong to joint family and $50 \%$ belong to nuclear family. In non-diabetic controls, $12 \%$ of cases have poor quality of life and among them $17 \%$ belong to joint family and $83 \%$ belong to nuclear family.

It is inferred that in physical component score the percentage of cases and controls having poor quality of life belong more to joint families, whereas equal when mental component score is taken into account.

\section{Duration of Diabetes/ PCS}

In our study, $6 \%$ of diabetic cases have 15 years of diabetes and among them $67 \%$ have poor quality of life.

\section{MCS}

In our study, $6 \%$ of diabetic cases have 15 years of diabetes and among them $34 \%$ have poor quality of life and $50 \%$ are in the age group of 5 years and below among whom $16 \%$ have poor quality of life.

From this we can infer that greater the duration of diabetics, poorer the quality of life which indicates a positive correlation.

\section{Type of Medication/ PCS}

In our study, $74 \%$ of diabetic cases are using oral medication and among them $19 \%$ have poor quality of life and $26 \%$ are using injectables and among these $15 \%$ have poor quality of life.

\section{MCS}

In our study, $74 \%$ of diabetic cases are using oral medication and among them $19 \%$ have poor quality of life and $26 \%$ are using injectables and among these $7 \%$ have poor quality of life.
From this we can infer that the percentage of individuals using injectables have poor quality of life when compared to those using oral medication similar to Faith et al study.12

\begin{tabular}{|c|c|c|}
\hline & PCS Diabetics & PCS Non-Diabetics \\
\hline Mean & 58.09524 & 63.45952 \\
\hline Observations & 100 & 100 \\
\hline Standard deviation & 14.65412 & 1.703582 \\
\hline $\mathrm{P}(\mathrm{T}<=\mathrm{t})$ two-tail & 0.016671 & \\
\hline
\end{tabular}

PCS of both the diabetics and non-diabetics were compared. Statistics clearly say that NDM have better quality of life compared with DM with $p$ value $(0.016671<0.05)$, which is significant and comparable to Dr. Faith et al study. ${ }^{12}$

\begin{tabular}{|c|c|c|}
\hline & MCS_DM & MCS_NDM \\
\hline Mean & 62.42 & 67.89333 \\
\hline Observations & 100 & 100 \\
\hline Standard deviation & 12.30523 & 1.291280262 \\
\hline $\mathrm{P}(\mathrm{T}<=\mathrm{t})$ two-tail & 0.001742 & \\
\hline
\end{tabular}

MCS of both the diabetics and non-diabetics were compared. Statistics clearly say that NDM have better quality of life compared to DM with $\mathrm{p}$ value $(0.001742<0.05)$, which is highly significant and comparable to Dr. Faith et al study. ${ }^{12}$

The mean (SD) SF-36 MCS was 62.42 (12.30), which is more than 51.1 (11.2) in Dr. Faith et al study. The mean (SD) SF-36 PCS was 58.09 (14.65), which is more than 42.9 (10.3) according to Dr. Faith et al ${ }^{12}$ study, suggesting higher mental than physical health quality of life.

\section{DISCUSSION}

In diabetic patients $80 \%$ were Hindus, $19 \%$ Christians, 1\% Jains, whereas in control group $86 \%$ were Hindus, $12 \%$ Christians and 2\% Muslims.

In diabetic patients $98 \%$ were married and $2 \%$ were unmarried, whereas in control group $82 \%$ were married and $8 \%$ were unmarried.

In diabetic patients $88 \%$ were educated and $12 \%$ were uneducated, whereas in control group $92 \%$ were educated and $8 \%$ were uneducated.

In diabetic patients 58\% were unemployed, $40 \%$ were employed and $2 \%$ were retired, whereas in control group $56 \%$ were employed and $44 \%$ were unemployed.

$72 \%$ of diabetic patients were residing in urban areas and $28 \%$ in rural areas, whereas $76 \%$ of control in urban area and $24 \%$ in rural area.

$54 \%$ of the diabetic patients hailed from nuclear family and $46 \%$ from joint family, whereas $60 \%$ of controls hailed from nuclear family and $40 \%$ from joint families. All the diabetic and non-diabetic patients belonged to middle class. $74 \%$ of the diabetic patients are using oral medication and $26 \%$ of the cases are using injectables. $96 \%$ of the diabetic cases have diabetes under control and $4 \%$ are uncontrolled cases. In $4 \%$ of uncontrolled diabetic patients, $6 \%$ are cardiac complicated and $96 \%$ of the cases are uncomplicated.

$54 \%$ of diabetic patients had less than five years duration of diabetes. $36 \%$ had 5 to 10 years of duration of diabetes. $6 \%$ cases had above 15 years and $4 \%$ had 10 to 15 years duration of diabetes. 


\section{Limitations}

One limitation of this study was that quality of life was subjectively assessed and no objective measures of QOL were obtained. Consequently, we are unable to ascertain the underlying causes of quality of life in this population. Another limitation is the cross-sectional design, which precludes us from establishing cause and effect in the associations examined.

\section{CONCLUSION}

1. The quality of life in diabetics is significantly lower in comparison to non-diabetic patients.

2. Mental parameters are significantly impaired than physical parameters.

3. Female patients have poor quality of life when compared to male patients.

4. There is a positive correlation between unemployment and quality of life in diabetics.

5. Patients on oral medication have a better quality of life when compared to those on injectables.

\section{REFERENCES}

[1] The Diabetes Atlas. International Diabetes Federation, 7th edn. Brussels: 2009.

[2] Abate N, Chandalia M. Ethnicity and type 2 diabetes: focus on Asian Indians. J Diabetes Complications 2001;15(6):320-7.

[3] World Health Organization. The World Health Organization Quality of Life (WHOQOL)-BREF, Geneva: World Health Organization, 2004.

[4] Varghese RT, Salini R, Abraham P, et al. Determinants of the quality of life among diabetic subjects in Kerala, India. Diabetes and Metabolic Syndrome: Clin Res Rev 2007;1(3):173-9.
[5] Undén AL, Elofsson S, Andréasson A, et al. Gender differences in self-rated health, quality of life, quality of care and metabolic control in patients with diabetes. Gend Med 2008;5(2):162-80.

[6] Speight J, Reaney MD, Barnard KD. Not all roads lead to Rome-a review of quality of life measurement in adults with diabetes. Diabet Med 2009;26(4):315-27.

[7] Rubin RR, Peyrot M. Quality of life and diabetes. Diabetes Metab Res Rev 1999;15(3):205-18.

[8] Bradley C, Speight J. Patient perceptions of diabetes and diabetes therapy: assessing quality of life. Diabetes Metab Res \& Rev 2002;18(Suppl 3):S64-S9.

[9] Imayama I, Plotnikoff RC, Courneya KS, et al. Determinants of quality of life in adults with type 1 and type 2 diabetes. Health Qual Life Outcomes 2011;9:115.

[10] Misra R, Lager J. Predictors of quality of life among adults with type 2 diabetes mellitus. J Diabetes Complications 2008;22(3):217-23.

[11] Ware JE Jr, Kosinski M, Keller SD. SF-36 Physical and Mental Health Summary Scales: a User's Manual. Boston, Mass: Health Assessment Lab, 1994.

[12] Luyster FS, Dunbar-Jacob J. Sleep quality and quality of life in adults with type 2 diabetes. Diabetes Educ 2011;37(3):347-55.

[13] Trikkalinou A, Papazafiropoulou AK, Melidonis A, Type 2 diabetes and quality of life. World J Diabetes 2017;8(4):120-9. 